\title{
Cell Therapy for Kidney Injury: Different Options and Mechanisms - Mesenchymal and Amniotic Fluid Stem Cells
}

\author{
Marina Morigia Paolo De Coppi ${ }^{b}$ \\ a IRCCS - Istituto di Ricerche Farmacologiche 'Mario Negri', Centro Anna Maria Astori, Science and Technology Park

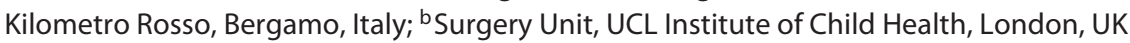

\section{Key Words}

Stem cells · Acute kidney injury · Amniotic fluid

\begin{abstract}
Background: Acute kidney injury (AKI) is emerging as a public health problem in developing and developed countries. It affects up to $7 \%$ of hospitalized patients, with a higher prevalence in critical care units. Despite major advances in preventive strategies and support measures, the mortality rate among patients remains higher than $50 \%$. Several pharmacological approaches to improve renal function and survival after an AKI episode have been largely unsuccessful in clinical practice. Summary: Stem cell-based therapy has provided new hopes of innovative interventions to enhance the limited capability of kidney regeneration in AKI. An important target for cell therapy is represented by tubular epithelial cells which after acute ischemic or toxic insults undergo dysfunction and detachment. Among adult stem cells, mesenchymal stromal/stem cells (MSC) are an attractive therapeutic tool by virtue of their unique biological properties, tropism for damaged tissues, and proregenerative capacity. In the present review, we discuss the mechanisms underlying the renoprotective effects of therapies with stem cells of different origins in preclinical models of AKI by evaluating new modalities by which MSC interact with damaged cells via the release of soluble factors and exosomes/microvesicles. Several biological effects, including antiapoptotic,
\end{abstract}

promitogenic, immunomodulatory, and anti-inflammatory activities, have been analyzed in renal tissue of AKI animals receiving stem cell treatments. The mechanisms of stem cell homing and engraftment to sites of tissue damage have also been discussed. Key Messages: The translation of preclinical data on stem cells into effective and safe new modalities of care is still limited, and further studies are needed before their application in patients with AKI.

c) 2014 S. Karger AG, Basel

\section{Introduction}

Stem cell-based therapy has emerged as a potential novel strategy for regeneration and repair of damaged tissues and organs. High expectations and excessive enthusiasm in regenerative medicine have evoked numerous clinical trials; however, the lack of clear preclinical data and the absence of systematic approaches and consistency have made it difficult to obtain unequivocal evidence of a robust clinical benefit $[1,2]$. More than 4,000 clinical trials employing different stem cell types are listed on the website www.clinicaltrials.gov, with over than 1,750 studies now open and 115 ongoing trials on mesenchymal stem cells (MSC) [1]. One of the most relevant testing grounds for looking at the regenerative potential of stem cell therapy [2] rests on studies of heart failure. These trials suggested that therapies with adult stem cells, including bone mar-

\section{KARGER}

E-Mail karger@karger.com

www.karger.com/nee (c) 2014 S. Karger AG, Base

$1660-2129 / 14 / 1262-0059 \$ 39.50 / 0$
Marina Morigi, $\mathrm{PhD}$

IRCCS - Istituto di Ricerche Farmacologiche 'Mario Negri'

Centro Anna Maria Astori, Science and Technology Park Kilometro Rosso

Via Stezzano 87, IT-24126 Bergamo (Italy)

E-Mail marina.morigi@marionegri.it 
row (BM)-derived MSC, were safe but the clinical efficacy observed was very modest. Many issues remain open and need to be clarified in experimental models before application in patients, including the choice of the best cell types, the route of administration, the timing of the intervention, and the cell number. Moreover, possible side effects associated with adult stem cell treatment as well as maldifferentiation and malignancies should be considered.

Stem cells derived from fetal tissue may have the advantage of being both more stable and more plastic and therefore offer a valid alternative to their adult counterpart. In particular stem cells could be derived from amniotic fluid (AF) at different developmental stages. These cells, named AF stem cells (AFSC), are characterized by expression of the surface antigen c-kit (CD117), possess great clonogenic potential, can be expanded in feeder layer-free, serum-rich conditions, and have intermediate characteristics between embryonic and adult stem cells [3]. Most importantly, AFSC display multilineage potential and are able, when injected systemically into HSACre, Smn (F7/F7) mice, to enhance muscle strength and improve the survival rate of the affected animals [4]. Their plasticity has also been demonstrated by the fact that, compared to postnatal cells, AFSC easily reprogram to a pluripotent status [5]. Beside their ability to give rise to different tissue, AFSC may also secrete different molecules when delivered to a damaged tissue or organ. In particular, we have observed that only AFSC, but not MSC, injected in an established rat model of necrotizing enterocolitis are capable not only of improving the survival and clinical status but also of dramatically ameliorating the gut structure and function. The latter has been achieved despite only minimal cell engraftment being observed. Ultimately, AFSC in this model of disease are capable of activating resident regulatory cells, which are responsible for the improvement of stem cell proliferation and inhibit apoptosis [6].

The story of stem cells as a tool to cure acute kidney injury (AKI) began in the last decade, focusing on the role of adult BM-derived stem cells in the promotion of kidney repair and tubular epithelial cell regeneration $[7,8]$.

\section{MSC-Based Therapy in AKI}

MSC, initially identified in the BM, have been recognized as an important component of the hematopoietic stem cell niche, where they regulate the self-renewal, maturation, and recruitment of hematopoietic stem cells to the vascular compartment through the release of cyto- kines and growth factors [8-10]. Human BM-MSC represent a heterogeneous rare population $(0.1-0.001 \%)$ of multipotent stem cells. By exposure to the appropriate inductive media, BM-MSC are able to differentiate into cells of mesodermal lineages such as adipocytes, chondrocytes, and osteocytes. The idea that these cells could also transdifferentiate into ectodermal or endodermal cells is now on the wane [10]. In culture, human BM-MSC express specific surface antigens like CD73, CD90, CD105, CD44, CD90, CD271, CD166, and Stro1 and a lack of hematopoietic markers. More recently, MSC have been identified in other tissues including peripheral blood, adipose tissue, skeletal muscle, umbilical cord wall/blood, and AF [8]. The finding that MSC share many markers with pericytes (perivascular cells that regulate the microvascular environment in multiple organs including the kidney) $[8,10$, 11] possibly suggests that MSC are ubiquitous and possibly stabilize the microvascular compartment.

Pioneer studies in animals and humans documented that extrarenal cells of BM origin participate in the process of kidney regeneration after acute injury [7]. Our group was the first to document the renoprotective effect of mouse BM-MSC, but not hematopoietic stem cells, given as cell therapy in an experimental model of AKI induced by the nephrotoxic antitumor drug cisplatin [12]. Infusion of MSC, 1 day after cisplatin injection, protected AKI mice from tubular injury and renal function deterioration by stimulating the proliferation of tubular cells [12]. As for the future perspectives of clinical translation, the therapeutic potential of human BM-MSC was studied in an experimental model of cisplatin-induced AKI in immunodeficient mice. Treatment with human BM-MSC in NOD/ SCID mice promoted renal function and tubular structural recovery and protected peritubular capillaries, thus resulting in increased animal survival (fig. 1) [13]. The paucity of MSC engrafting the damaged renal tissues and their preferential localization almost exclusively in peritubular areas and less frequently in the context of tubular epithelium support the concept that MSC act via transdifferentiation-independent mechanisms $[12,13]$. Studies in the ischemia reperfusion model in rats have documented that BM-MSC exert renoprotective effects via paracrine production of prosurvival, mitogenic, anti-inflammatory, and vasculotropic factors [14]. The assertion that MSC secrete soluble factors able to stimulate renal regeneration is based on data showing that repeated infusions of MSC-conditioned medium in cisplatin mice limit tubular injury and apoptosis, preserving the animals' life span [15]. In agreement with these findings, there is also evidence indicating that insulin growth factor-1 (IGF-1) and vascular endothe-
Morigi/De Coppi 


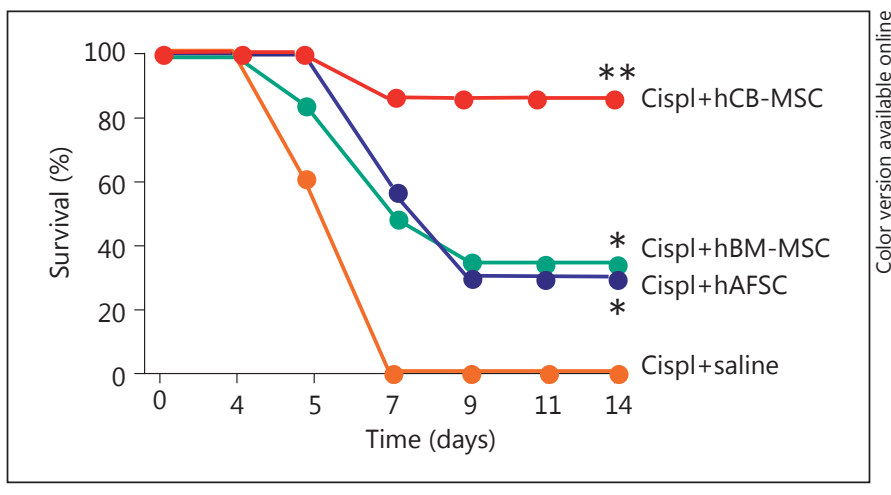

Fig. 1 Effects of stem cells of different origins on the survival of immunodeficient mice with cisplatin-induced AKI. Immunodeficient NOD/SCID mice were injected with cisplatin (Cispl) and $24 \mathrm{~h}$ later they were intravenously infused with human (h) BMMSC, hCB-MSC, or hAFSC. ${ }^{*} \mathrm{p}<0.02$ vs. Cispl+saline; ${ }^{* *} \mathrm{p}<0.001$ vs. Cispl+saline.

lial growth factor (VEGF) are instrumental in the regenerative processes evoked by MSC in AKI animals by genesilencing experiments $[16,17]$. Knockdown of IGF-1 and VEGF expression in BM-MSC markedly limits their renoprotective effects in animals with AKI $[16,17]$, highlighting the fundamental role of MSC in the process of renal repair through a local paracrine action. An additional novel mechanism of specific cell-to-cell communication via microvesicles/exosomes has been recently found to act in concert with the local release of growth factors in processes of MSC-dependent regeneration [18, 19]. The finding that the activity of IGF-1 released by MSC [16] is further amplified by mRNA transfer of the corresponding receptor IGF-1R by microvesicles/exosomes to damaged tubular cells can explain how a low number of MSC homing to the kidney can promote powerful recovery from AKI $[8,18]$.

In search of new sources of more accessible and effective MSC, we tested the effects of adipose tissue and human cord blood (CB)-derived MSC in immunodeficient mice with AKI. In contrast to a recent study [20], we observed no renoprotective effects in mice receiving human adipose tissue-MSC isolated by 2 different donors [8]. Human CB-MSC represent a recent alternative reservoir which is extremely rich in stem and progenitor cells. They are similar to MSC of BM origin in terms of their morphological characteristics, immune phenotype, and differentiation into osteocytes and chondrocytes but do not possess adipogenic potential [21]. Human CB-MSC treatment in mice with cisplatin-induced AKI remarkably ameliorated renal function and tubular damage; however, their influence on animal survival was considerably stron- ger (fig. 1) with respect to the effect of BM cells [21]. These effects appear to be mediated by a more efficient paracrine action of human CB-MSC on tubular cells, i.e. lowering of oxidative stress, apoptosis, and inflammation via the activation of AKT-dependent prosurvival pathways [21].

\section{AFSC-Based Therapy}

The potential of AFSC to contribute to kidney development has been explored in the last few years. Using a mesenchymal/epithelial differentiation protocol previously applied to demonstrate the renal differentiation potential of kidney stem cells, it was documented that AFSC could differentiate towards renal lineages. AFSC sequentially grown first in mesenchymal differentiation medium containing EGF and PDGF-BB and subsequently in epithelial differentiation medium containing HGF and FGF4 reduced the expression of pluripotency markers (i.e. Oct4 and c-Kit) and switched on the expression of epithelial (i.e. $\mathrm{CD} 51$ and $\mathrm{ZO}-1$ ) and podocyte markers (i.e. CD2AP and NPHS2) [22]. Similarly, AFSC have also been shown to contribute to the development of primordial kidney structures during in vitro organogenesis; undifferentiated human AFSC injected into a mouse embryonic kidney cultured ex vivo are able to integrate into primordial kidney structures including renal vesicles and C- and Sshaped bodies and participate in all steps of nephrogenesis. Gene expression analysis confirmed the expression of early kidney markers for zona occludens-1, claudin, and glial-derived neurotrophic factor [23]. Similar data were reproduced later by a different group, which formed chimeric renal structures by mixing murine embryonic kidney cells with human AFSC. Interestingly, they demonstrated that human AFSC differentiation to renal tissue is regulated by two kinase complexes, i.e. the mammalian targets of rapamycin 1 and 2 [24].

However, direct differentiation may unfortunately be limited to embryonic development, and when AFSC are injected into the postnatal kidney their direct contribution to specialized tissue is usually minimal. Nevertheless, they may contribute to tissue regeneration through a paracrine action, which is evident when they are delivered to damaged kidneys. Indeed, human AFSC were shown to provide a protective effect in an acute tubular necrosis mouse model where they were able to decrease creatinine and BUN blood levels. Histologically, these results were confirmed by the decrease in the number of damaged tubules with an associated reduction of apoptosis within the tissue and the promotion of proliferation of tubular epi- 
thelial cells [25]. The same group showed that AFSC could be also useful in a model of chronic damage. In a mouse model of Alport syndrome (Col4a5-/- mice), AFSC were in fact capable of prolonging the animals' survival, ameliorating the decline in kidney function, and delaying the progression of glomerular sclerosis and interstitial fibrosis [26]. The latter was also observed when human AFSC were injected in a murine model of unilateral ureteral obstruction (UUO). In this animal model, human AFSC were able to provide a protective effect and ameliorate interstitial fibrosis as demonstrated by an increase in microvascular density. The effect of human AFSC may be mediated by the modulation of specific growth factors since, in the treated animals, analyses of kidney tissues revealed prominent VEGF expression in glomerular podocytes and tubular epithelial cells. Specifically, the levels of VEGF were significantly reduced in both the UUO group and the human AFSC group compared to the control group; however, VEGF expression was higher in the human AFSC group compared to the UUO group. In the same animals, Western blot analysis showed that hypoxia-inducible factor-1 $\alpha$ (HIF-1 $\alpha$ ) protein levels were decreased in the human AFSC group compared to the UUO group, which clearly indicated that human AFSC transplantation alleviated the hypoxic conditions associated with UUO. Finally, transforming growth factor- $\beta_{1}$ (TGF- $\beta_{1}$ ) protein expression was markedly reduced in the human AFSC group compared to the UUO group [27]. Interestingly, AFSC could act through pathways different from those of MSC in a model of acute renal failure even if the final regenerative potential may be not so dissimilar. Indeed, it has been described that the functional recovery obtained in mice with glycerol-induced AKI after intravenous injection of human AFSC is similar to that obtained by infusion of MSC. The rapid normalization of renal function, which followed the cell infusion, was mainly related to the fact that both stem cell types showed enhanced tubular cell proliferation and reduced apoptosis. However, it appeared that MSC were more efficient in inducing proliferation than AF-derived stem cells which, in contrast, were more antiapoptotic. Moreover, both cell types were found to accumulate within the peritubular capillaries and the interstitium, but AFSC were more persistent than MSC. In parallel, the experiments conducted in vitro showed that the two cell types produced different cytokines and growth factors, suggesting that a combination of different mediators is involved in their biological actions [28].

Our group has also shown that human AFSC engraft in the cisplatin-injured kidney, where they localize predominantly in the peritubular region without acquiring tubular epithelial markers [29]. Even if they did not differentiate into renal tissue, human AFSC improved renal function and limited tubular damage, with the overall result of prolonging the animals' survival. Human AFSC exerted antiapoptotic effects, activated AKT, and stimulated the proliferation of tubular cells possibly via the local release of factors, including interleukin-6, VEGF, and stromal cell-derived factor-1, which we documented in vitro to be produced by human AFSC. Moreover, the therapeutic potential of human AFSC could be enhanced by cell pretreatment with glial cell line-derived neurotrophic factor, which markedly ameliorated renal function and tubular injury by increasing stem cell homing to the tubule interstitial compartment.

\section{Conclusions}

The translation of preclinical data on stem cells into robust, effective, and safe new modalities of care is still limited. It is possible that, given their variable plasticity and their specific profile of secretory factors, different stem cell types could be used in different kidney diseases. MSC may have considerable clinical potential for the treatment of AKI thanks to their ability to produce multiple regulatory and trophic factors, generally referred to as MSC secretome. In this context, phase I clinical trials to evaluate the safety and efficacy of allogeneic MSC administration are ongoing $[8,30]$.

Alternatively, data obtained from embryonic kidneys seems to indicate that AFSC are capable of differentiating into kidney cells. While not clearly demonstrated yet, AFSC may also have a similar ability when injected into the postnatal kidney, maybe through reprogramming. If the latter is confirmed, AFSC may have the advantage of being used both for the promotion of resident cell proliferation and for direct regeneration.

\section{Acknowledgements}

Manuela Passera helped prepare the manuscript. We also thank Dr. Cinzia Rota, Barbara Imberti, and Antonella Piccinelli for their contributions. Dr. Paolo De Coppi is supported by the Great Ormond Street Hospital Children's Charity. This work was partially supported by a European Commission grant (project No. HEALTH-F4-2012-305436).
Morigi/De Coppi 


\section{References}

1 Daley GQ: The promise and perils of stem cell therapeutics. Cell Stem Cell 2012;10:740-749.

$\checkmark 2$ Ilic D, Polak J: Stem cell based therapy where are we going? Lancet 2012;379:877878.

-3 De Coppi P, Bartsch G Jr, Siddiqui MM, Xu T, Santos CC, Perin L, Mostoslavsky G, Serre AC, Snyder EY, Yoo JJ, Furth ME, Soker S, Atala A: Isolation of amniotic stem cell lines with potential for therapy. Nat Biotechnol 2007;25:100-106.

-4 Piccoli M, Franzin C, Bertin E, Urbani L, Blaauw B, Repele A, Taschin E, Cenedese A, Zanon GF, Andre-Schmutz I, Rosato A, Melki J, Cavazzana-Calvo M, Pozzobon M, De Coppi P: Amniotic fluid stem cells restore the muscle cell niche in a HSA-Cre, Smn(F7/F7) mouse model. Stem Cells 2012;30:1675-1684.

5 Moschidou D, Mukherjee S, Blundell MP, Drews K, Jones GN, Abdulrazzak H, Nowakowska B, Phoolchund A, Lay K, Ramasamy TS, Cananzi M, Nettersheim D, Sullivan M, Frost J, Moore G, Vermeesch JR, Fisk NM, Thrasher AJ, Atala A, Adjaye J, Schorle H, De Coppi P, Guillot PV: Valproic acid confers functional pluripotency to human amniotic fluid stem cells in a transgene-free approach. Mol Ther 2012;20:1953-1967.

-6 Zani A, Cananzi M, Fascetti-Leon F, Lauriti G, Smith VV, Bollini S, Ghionzoli M, D’Arrigo A, Pozzobon M, Piccoli M, Hicks A, Wells J, Siow B, Sebire NJ, Bishop C, Leon A, Atala A, Lythgoe MF, Pierro A, Eaton S, De Coppi P: Amniotic fluid stem cells improve survival and enhance repair of damaged intestine in necrotising enterocolitis via a COX-2 dependent mechanism. Gut 2013;63:300-309.

-7 Poulsom R, Forbes SJ, Hodivala-Dilke K, Ryan E, Wyles S, Navaratnarasah S, Jeffery R, Hunt T, Alison M, Cook T, Pusey C, Wright NA: Bone marrow contributes to renal parenchymal turnover and regeneration. J Pathol 2001;195:229-235.

-8 Morigi M, Benigni A: Mesenchymal stem cells and kidney repair. Nephrol Dial Transplant 2013;28:788-793.

-9 Uccelli A, Moretta L, Pistoia V: Mesenchymal stem cells in health and disease. Nat Rev Immunol 2008;8:726-736.

10 Bianco P, Cao X, Frenette PS, Mao JJ, Robey PG, Simmons PJ, Wang CY: The meaning, the sense and the significance: translating the science of mesenchymal stem cells into medicine. Nat Med 2013;19:35-42.

\section{1} Crisan M, Yap S, Casteilla L, Chen CW, Corselli M, Park TS, Andriolo G, Sun B, Zheng B, Zhang L, Norotte C, Teng PN, Traas J, Schugar R, Deasy BM, Badylak S, Buhring HJ, Giacobino JP, Lazzari L, Huard J, Peault B: A perivascular origin for mesenchymal stem cells in multiple human organs. Cell Stem Cell 2008;3:301-313.

12 Morigi M, Imberti B, Zoja C, Corna D, Tomasoni S, Abbate M, Rottoli D, Angioletti S, Benigni A, Perico N, Alison M, Remuzzi G: Mesenchymal stem cells are renotropic, helping to repair the kidney and improve function in acute renal failure. J Am Soc Nephrol 2004;15: 1794-1804

13 Morigi $\mathrm{M}$, Introna $\mathrm{M}$, Imberti $\mathrm{B}$, Corna $\mathrm{D}$, Abbate M, Rota C, Rottoli D, Benigni A, Perico N, Zoja C, Rambaldi A, Remuzzi A, Remuzzi G: Human bone marrow mesenchymal stem cells accelerate recovery of acute renal injury and prolong survival in mice. Stem Cells 2008;26:2075-2082.

14 Togel F, Hu Z, Weiss K, Isaac J, Lange C, Westenfelder C: Administered mesenchymal stem cells protect against ischemic acute renal failure through differentiation-independent mechanisms. Am J Physiol Renal Physiol 2005;289:F31-F42.

15 Bi B, Schmitt R, Israilova $M$, Nishio $H$, Cantley LG: Stromal cells protect against acute tubular injury via an endocrine effect. J Am Soc Nephrol 2007;18:2486-2496.

16 Imberti B, Morigi M, Tomasoni S, Rota C, Corna D, Longaretti L, Rottoli D, Valsecchi F, Benigni A, Wang J, Abbate M, Zoja C, Remuzzi G: Insulin-like growth factor-1 sustains stem cell mediated renal repair. J Am Soc Nephrol 2007;18:2921-2928.

17 Togel F, Cohen A, Zhang P, Yang Y, Hu Z, Westenfelder C: Autologous and allogeneic marrow stromal cells are safe and effective for the treatment of acute kidney injury. Stem Cells Dev 2009;18:475-485.

18 Tomasoni S, Longaretti, L, Rota C, Morigi M, Conti S, Gotti E, Capelli C, Introna M, Remuzzi G, Benigni A: Transfer of growth factor receptor mRNA via exosomes unravels the regenerative effect of mesenchymal stem cells. Stem Cells Dev 2013;22:772-780.

19 Bruno S, Grange C, Deregibus MC, Calogero RA, Saviozzi S, Collino F, Morando L, Busca A, Falda M, Bussolati B, Tetta C, Camussi G: Mesenchymal stem cell-derived microvesicles protect against acute tubular injury. J Am Soc Nephrol 2009;20:1053-1067.

-20 Kim JH, Park DJ, Yun JC, Jung MH, Yeo HD, Kim HJ, Kim DW, Yang JI, Lee GW, Jeong SH, Roh GS, Chang SH: Human adipose tissue-derived mesenchymal stem cells protect kidneys from cisplatin nephrotoxicity in rats. Am J Physiol Renal Physiol 2012;302:F1141F1150.
21 Morigi M, Rota C, Montemurro T, Montelatici E, Lo Cicero V, Imberti B, Abbate M, Zoja C, Cassis P, Longaretti L, Rebulla P, Introna M, Capelli C, Benigni A, Remuzzi G, Lazzari L: Life-sparing effect of human cord bloodmesenchymal stem cells in experimental acute kidney injury. Stem Cells 2010;28:513522.

22 Siegel N, Valli A, Fuchs C, Rosner M, Hengstschlager M: Induction of mesenchymal/epithelial marker expression in human amniotic fluid stem cells. Reprod Biomed Online 2009; 19:838-846.

23 Perin L, Giuliani S, Jin D, Sedrakyan S, Carraro, G, Habibian, R, Warburton, D, Atala A, De Filippo RE: Renal differentiation of amniotic fluid stem cells. Cell Prolif 2007;40:936948.

24 Siegel N, Rosner M, Unbekandt M, Fuchs C, Slabina N, Dolznig H, Davies JA, Lubec G, Hengstschlager M: Contribution of human amniotic fluid stem cells to renal tissue formation depends on mTOR. Hum Mol Genet 2010;19:3320-3331.

25 Perin L, Sedrakyan S, Giuliani S, Da Sacco S, Carraro G, Shiri L, Lemley KV, Rosol M, Wu S, Atala A, Warburton D, De Filippo RE: Protective effect of human amniotic fluid stem cells in an immunodeficient mouse model of acute tubular necrosis. PLoS One 2010; 5:e9357.

26 Sedrakyan S, Da Sacco S, Milanesi A, Shiri L, Petrosyan A, Varimezova R, Warburton D, Lemley KV, De Filippo RE, Perin L: Injection of amniotic fluid stem cells delays progression of renal fibrosis. J Am Soc Nephrol 2012;23: 661-673.

-27 Sun D, Bu L, Liu C, Yin Z, Zhou X, Li X, Xiao A: Therapeutic effects of human amniotic fluid-derived stem cells on renal interstitial fibrosis in a murine model of unilateral ureteral obstruction. PLoS One 2013;8:e65042.

28 Hauser PV, De Fazio R, Bruno S, Sdei S, Grange C, Bussolati B, Benedetto C, Camussi G: Stem cells derived from human amniotic fluid contribute to acute kidney injury recovery. Am J Pathol 2010;177:2011-2021.

29 Rota C, Imberti B, Pozzobon M, Piccoli M, De Coppi P, Atala A, Gagliardini E, Xinaris C, Benedetti V, Fabricio AS, Squarcina E, Abbate M, Benigni A, Remuzzi G, Morigi M: Human amniotic fluid stem cell preconditioning improves their regenerative potential. Stem Cells Dev 2012;21:1911-1923.

-30 Togel FE, Westenfelder C: Mesenchymal stem cells: a new therapeutic tool for AKI. Nat Rev Nephrol 2010;6:179-183. 